\title{
Gestão da pesca artesanal na Costa da Paraíba, Brasil: uma abordagem utilizando o Processo Analítico Hierárquico *
}

\author{
Artisanal fisheries management in Paraíba Coast, Brazil: \\ an Analytic Hierarchy Process approach
}

\author{
Eugenio Pacelli Nunes Paulo Júnior ${ }^{\circledR, 1}$, Josias Henrique de Amorim Xavier ${ }^{2}$, \\ Roberto Sassi ${ }^{2}$, Ricardo de Souza Rosa ${ }^{2}$
}

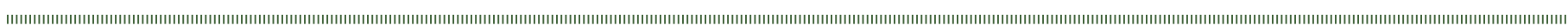

\section{RESUMO}

O potencial da pesca vem sendo afetado devido à depleção dos recursos naturais nos ambientes aquáticos, principalmente em decorrência da sobrepesca. A análise da Gestão de Recursos tem se tornado um fator relevante, já que a própria atividade pesqueira pode causar impactos negativos locais. Este tema tem sido bastante abordado em pesquisas ao redor do mundo, evidenciando a importância de uma abordagem mais ampla que englobe diversos setores da gestão pesqueira. Desta forma, a problemática transcende as questóes ambientais e envolve aspectos socioeconômicos e políticos, como ocorre em relação à pesca na Costa do Estado da Paraíba, Nordeste do Brasil. O objetivo deste estudo foi caracterizar a gestáo da pesca artesanal e propor alternativas na busca de esforços para alcançar a sustentabilidade da pesca. Foram realizadas entrevistas com pescadores, pesquisadores, gestores públicos e outros atores sociais, os quais elencaram alternativas de gestão e as julgaram de acordo com seu grau de importância. As alternativas foram priorizadas através do Processo Analítico Hierárquico (PAH). Obtivemos doze alternativas, das quais se destacaram a gestão compartilhada (18\%), frente às novas mudanças do setor de pesca brasileiro, a preservação das espécies (16\%), como alternativa para melhorar as condições ambientais, e a fiscalização e monitoramento (11\%). Deste modo, o maior interesse e envolvimento dos usuários nos processos de tomada de decisão podem ajudar a minimizar os conflitos entre os participantes e fortalecer a organização sociopolítica da classe dos pescadores artesanais.

Palavras-Chave: Zona costeira, Recursos pesqueiros, Gestão compartilhada, Conservação.

\section{ABSTRACT}

The potential of fisheries has been affected due to loss of natural resources in aquatic environments, especially due to overfishing. The analysis of the resource management becomes a relevant factor, since the fishing activity itself may cause local negative impacts. This subject has been treated around the world, emphasizing the importance of a broader approach that encompasses the various sectors of fisheries management. Thus, the problem is beyond environmental issues, involving also socio-economic and political aspects, as represented in the fisheries along the coastal state of Paraiba, Northeastern Brazil. This study aims to characterize management on artisanal fisheries and stimulate the development

@ - Corresponding author: eugenioepacelli@gmail.com

1 - Universidade Federal da Paraíba, Programa de Pós-Graduaçäo em Desenvolvimento e Meio Ambiente - PRODEMA (Mestrado), Centro de Ciências Exatas e da Natureza. Cidade Universitária - Campus I, 58059-900 João Pessoa, PB, Brasil. e-mail: engenioepacelli@gmail.com

2 - Universidade Federal da Paraíba, Departamento de Sistemática e Ecologia, Centro de Ciências Exatas e da Natureza. Cidade Universitária - Campus I, 58051-900 Joäo Pessoa,PB, Brasil.e-mails:Xavier-josiasxavier@gmail.com; Sassi-sassi_rs@yahoo.com.br; Rosa-rsrosa@dse.ufpb.br 
of sustainable alternatives, through processes of social construction and policy-making with the participation of stakeholders involved in fishery. We used interviews with fishermen, scientists, resource managers and others. By gathering the answers, we constructed a diagram with all possible alternatives to accomplish a sustainable fishery management, and evaluate priorities between alternatives, all by registered answers. We used the Analytic Hierarchy Process (AHP) as a working tool that deals with multiple management criteria. As a result, we obtained twelve alternatives for the management; among them, co-management was considered the most important alternative (18\% of priority) to face the new changes in the fishery Brazilian sector, followed by the emphasis on the preservation of species (16\%) as the main alternative currently used to improve the environmental and fishing condition, and the inspection and monitoring (11\%) of artisanal fisheries. Overall, the management alternative seems to be linked by common interests. Thus, we strongly recommend the stimulation of co-management among stakeholders. The increased interest and involvement of users in decision-making processes can help to minimize conflicts between the participants and strengthen the socio-political organization of the artisanal fishermen class.

Keywords: Coastal zone, Fisheries resource, Co-management, Conservation.

\section{INTRODUÇÃO}

A gestão pesqueira tem atravessado tempos turbulentos no Brasil e no mundo (Rose, 1997). A redução dos estoques, o crescimento populacional humano e a concentraçáo da população em áreas costeiras são alguns fatores que afetam o gerenciamento pesqueiro e a criação de políticas públicas em todo o mundo, incluindo o Brasil (Pauly et al., 2002; Freire \& Pauly, 2010). No Estado da Paraíba, órgãos públicos gestores da pesca (MPA, IBAMA, Capitania dos Portos - Marinha, ICMBIO, MMA, Ministério do Trabalho) frequentemente enfrentam problemas quanto ao ordenamento, fiscalização, compartilhamento de informações e censos estatísticos da produção pesqueira.

Nas últimas décadas, diversos impactos foram identificados decorrentes de pressóes antrópicas na zona costeira, especialmente a sobreexploração de recursos. Mais recentemente, incentivos do governo federal brasileiro proporcionaram a expansão da pesca, que levou ao sobre-dimensionamento dos meios de produção e à sobreexploração de grande parte dos estoques pesqueiros (Bezerra \& Munhoz, 2000). Este modelo aplicado no Brasil gerou um crescimento desordenado do setor pesqueiro, com altos níveis de exclusáo social, empobrecimento da pesca artesanal e da infra-estrutura, além de resultar no declínio dos estoques (Cardoso, 2001).

Especialistas em gestão de pesca reconhecem que as causas da sobreexploração dos recursos pesqueiros e da degradação do ambiente costeiro são frequentemente de origem social, econômica, institucional e/ou política. As principais preocupaçóes são os direcionamentos dos benefícios gerados pelos recursos pesqueiros em relação à saúde humana e conservação desses recursos a serem utilizados pelas geraçóes futuras (Pomeroy, 1995). De acordo com a FAO (2010), os problemas no setor pesqueiro de países em desenvolvimento usualmente estáo relacionados à falta de organizaçáo e estrutura, ausência de dados sobre os recursos utilizados, além de fiscalização, políticas e gestão inadequadas. Pomeroy \& Berkes (1997) sugerem que parte dos conflitos é resultante do modelo de gestão centralizado, onde existe pouco ou nenhum envolvimento dos usuários no processo de participação e na tomada de decisóes. $\mathrm{Na}$ gestấo centralizada, os gestores podem agir de acordo com seus próprios interesses, dando ênfase a sua área de formação ou atuação (Pascoe et al., 2009). Esse sistema acaba por favorecer os interesses da classe empresarial, enquanto o modelo de desenvolvimento se baseia na exploração máxima dos recursos naturais e na distribuição não igualitária de renda (Diegues, 2001).

Diante desse quadro, estudiosos afirmam que um modelo descentralizado de gestão seria mais adequado às nossas metas atuais de sustentabilidade. As prerrogativas dos modelos descentralizados, com a efetiva participação dos atores envolvidos, estão documentadas em vários trabalhos no âmbito global (Pomeroy, 1995; Pomeroy \& Berkes, 1997; Jentoft et al., 1998; Pomeroy et al., 2004). Em virtude da variabilidade da legislação aplicável aos ambientes aquáticos e seus recursos bióticos, a gestão da atividade pesqueira torna-se ainda mais complexa. A nova abordagem de gestão é constituída pela soma de arranjos jurídicos, sociais, econômicos e políticos utilizados para gerenciar a pesca de forma sustentável.

Os recursos produzidos pela pesca artesanal marinha são de extrema importância para as comunidades que dela dependem, como fonte de alimento, emprego, renda e lazer. Devido à ideia de que os recursos pesqueiros são, em muitas situaçôes, de propriedade comum e de livre acesso (Ostrom, 1990), são gerados conflitos quanto às formas de utilização por múltiplos usuários. Com base nos aspectos sociais, econômicos, políticos e ambientais, o presente estudo teve como objetivo geral caracterizar a gestão da pesca artesanal, avaliando alternativas para alcançar a sustentabilidade da pesca na Costa da Paraíba, Brasil. Como objetivos específicos, propôs-se (1) elencar as alternativas de gestão de acordo com a realidade local, e (2) selecionar, com base em critérios decididos pelos próprios atores sociais, através do Processo Analítico Hierárquico (PAH), as alternativas prioritárias para a gestáo da pesca.

\section{METODOLOGIA}

\section{1. Área de Estudo}

O Estado da Paraíba possui uma das menores extensóes de costa, dentre os estados brasileiros. Com aproximadamente $140 \mathrm{~km}$ de extensão, a Costa paraibana representa menos de $2 \%$ do total nacional. Seu litoral estende-se entre as coordenadas $6^{\circ} 31^{\prime} 08.00^{\prime \prime} \mathrm{S} / 34^{\circ} 58^{\prime} 02.00^{\prime \prime W}$ e $7^{\circ} 34^{\prime} 43.13^{\prime \prime S / ~}$ $34^{\circ} 49^{\prime} 54.81^{\prime \prime W}$, limitando-se ao Norte pelo estuário do 
rio Guajú, divisa com Rio Grande do Norte, e ao Sul pelo estuário do rio Goiana, divisa com Pernambuco (figura 1). $\mathrm{O}$ trabalho foi realizado junto às comunidades, colônias e associaçôes de pescadores artesanais. Das 44 colônias de pesca do Estado, 14 se distribuem ao longo de 12 municípios da zona costeira (figura 1). Foram selecionadas 26 comunidades destas 14 colônias costeiras, que se constituíram no objeto de estudo deste trabalho (tabela 1 ).

\subsection{Estabelecimento das alternativas para gestáo}

Entrevistas foram realizadas a partir de questionários semiestruturados nas principais comunidades de pesca do Estado, contemplando as diversas esferas da sociedade: pescadores, gestores públicos, empresários do setor, pesquisadores de instituiçốes acadêmicas e outros atores sociais envolvidos na pesca (tabela 2).

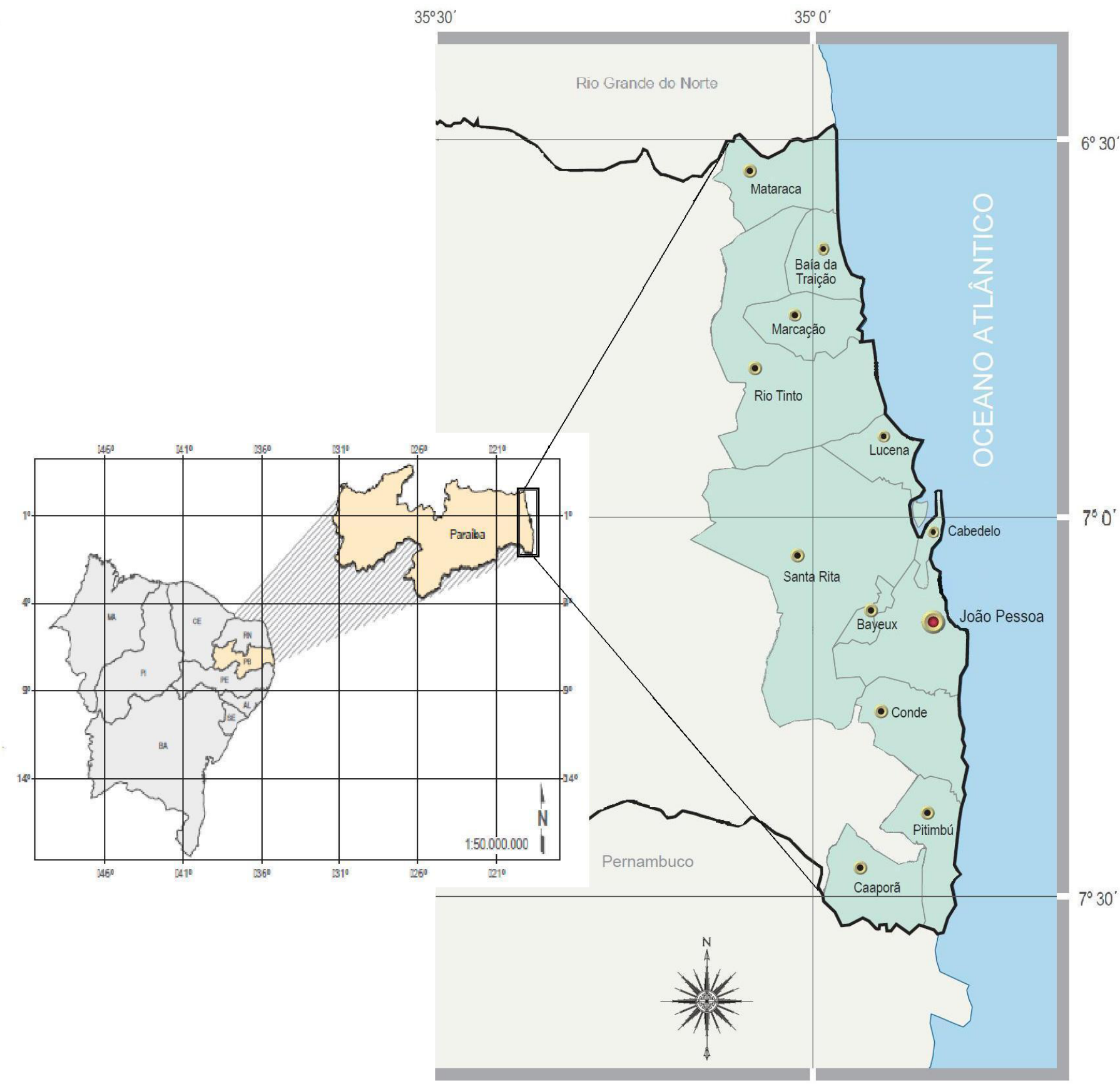

Figura 1. Municípios da Costa da Paraíba onde se localizam as colônias de pescadores selecionadas para o estudo. Fonte: adaptado de AESA (2010).

Figure 1. Municipalities of the coast of Paraiba where are located the fishing colonies selected for the study. Source: AESA (2010), modified. 
Tabela 1. Colônias de pescadores do litoral da Paraíba, seus respectivos municípios e as principais comunidades amostradas.

Table 1. Colonies of fishermen on the coast of Paraiba, their cities and major communities sampled.

\begin{tabular}{|c|c|c|c|}
\hline $\mathbf{Z n}^{*}-$ & - Colônias de Pescadores** & Município & Comunidades amostradas \\
\hline $\mathrm{Z} 1$ & "Comandante Oscar Gonçalves" & Baía da Traição & Baía da Traição \\
\hline $\mathrm{Z} 2$ & "Presidente Epitácio Pessoa" & Cabedelo & Camalaú, Resnascer, Jacaré, Porto (Campelo) \\
\hline Z3 & "André Vital de Negreiros" & João Pessoa & Tambaú, Penha, Jacarapé, Barra de Gramame \\
\hline $\mathrm{Z} 4$ & "Henrique Dias" & Pitimbú & Pitimbú \\
\hline $\mathrm{Z} 5$ & "Benjamin Constant" & Lucena & Lucena \\
\hline Z 6 & "Arnaldo Luz" & Bayeux & Porto do Moinho, Casa Branca, São Lourenço \\
\hline Z9 & "João Alves dos Santos" & Conde & Jacumã \\
\hline $\mathrm{Z} 10$ & "Manoel Augusto de Lima" & Pitimbú & Acaú \\
\hline $\mathrm{Z} 11$ & "Antônio Elias Pessoa" & Santa Rita & Forte Velho, Livramento, Ribeira I, II, III \\
\hline $\mathrm{Z} 12$ & "Eduardo Francisco da Silva" & Caaporã & Porto de Congaçari \\
\hline Z 13 & "Antônio de Brito" & Rio Tinto & Barra de Mamanguape \\
\hline Z 14 & "Antônio Izidoro da Silva" & Marcação & Tramataia \\
\hline $\mathrm{Z} 17$ & "Walfredo Medeiros da Costa" & Mataraca & Barra de Camaratuba \\
\hline Z 19 & "Antônio Felipe dos Santos" & Lucena & Costinha \\
\hline
\end{tabular}

* Simbologia utilizada pelas colônias de pescadores para delimitar as zonas de pesca e numerá-las na ordem de sua criação dentro de cada território estadual da Federaçáo. ${ }^{* *}$ Nome fantasia.

Tabela 2. Categorias de atores sociais que participaram das entrevistas sobre a gestáo da pesca artesanal na costa da Paraíba

Table 2. Stakeholders categories that participate of interviews on artisanal fisheries management in Paraiba Coast

\begin{tabular}{|c|c|}
\hline Categorias ( $\mathrm{n}^{\circ}$ questionários) & Órgãos e Instituições pesquisadas \\
\hline Pescadores (107) & Comunidades pesqueiras \\
\hline Presidentes das colônias (14) & Colônias de pescadores \\
\hline \multirow{3}{*}{ Pesquisadores (14) } & Universidade Federal da Paraíba (UFPB) \\
\hline & Universidade Estadual da Paraíba (UEPB) \\
\hline & Instituto Federal de Educação, Ciência e Tecnologia da Paraíba (IFPB) \\
\hline \multirow{5}{*}{ Gestores públicos (10) } & $\begin{array}{l}\text { Instituto Brasileiro do Meio Ambiente e dos Recursos Naturais Renováveis } \\
\text { (IBAMA) }\end{array}$ \\
\hline & Ministério da Pesca e Aquicultura (MPA-PB) \\
\hline & Instituto Chico Mendes de Conservação da Biodiversidade (ICMBIO) \\
\hline & Capitania dos Portos (Marinha) \\
\hline & Secretarias de Meio Ambiente e Pesca dos municípios pesquisados \\
\hline Empresários (4) & Estabelecimentos comerciais de pesca \\
\hline Outros (2) & Sindicato dos Marítimos e Organização Não-Governamental (ONG) \\
\hline
\end{tabular}


As entrevistas ocorreram entre os meses de outubro de 2009 e novembro de 2010, com 151 atores sociais envolvidos no setor pesqueiro, entrevistados de forma aleatória, sendo 121 pescadores e 30 entre os demais participantes. O conteúdo abordado nas entrevistas teve o objetivo de criar e priorizar alternativas para a gestão da pesca artesanal na Costa da Paraíba. Para isso, duas etapas foram realizadas. $\mathrm{Na}$ primeira etapa, a pergunta norteadora direcionada aos participantes foi: "o que poderia ser feito para melhorar a situação da pesca artesanal no litoral do Estado?”. As respostas foram transcritas e analisadas. As alternativas para a gestão foram isoladas e organizadas em um diagrama hierárquico, denominado "Árvore de decisão". $\mathrm{Na}$ segunda etapa, os participantes foram questionados quanto ao grau de prioridade que atribuíam a cada alternativa.

\subsection{O Processo Analítico Hierárquico (PAH)}

O Processo Analítico Hierárquico (PAH), do inglês Analytic Hierarchy Process (AHP), foi desenvolvido por Thomas Saaty (1977) e constitui um método prático e confiável de hierarquização de alternativas de gestáo. Tem sido usado consideravelmente para a definição e análise de usuários (ou tomadas de decisão), em muitas áreas com problemas complexos de decisão e avaliação, envolvendo trade-offs de objetivos múltiplos (Mardle et al., 2004).

$\mathrm{O}$ PAH trata um problema através de uma estruturação hierárquica, objetivando priorizar as alternativas através da análise de diversos fatores. Este processo tem três etapas: (1) a estruturação hierárquica, onde são definidos os critérios e alternativas que podem satisfazer a meta principal; (2) a comparação paritária, em que os elementos de decisão são transformados em matrizes e analisados quanto à sua prioridade em cada nível hierárquico; e a (3) síntese de prioridades, onde cada alternativa é elencada (parcial ou globalmente) por ordem de importância para alcançar a meta principal (Saaty, 1991).

A estruturação hierárquica consiste na definição da meta principal, ou objetivo global, e na decomposição do problema em vários níveis de hierarquia, contendo elementos inter-relacionados (critérios e alternativas), como mostra a figura 2 (Saaty, 1991). No presente estudo, o objetivo global foi atingir a gestão da pesca artesanal. As alternativas foram isoladas a partir das respostas dos entrevistados e agrupadas em quatro critérios principais: ambiental (C1), econômico (C2), social (C3) e político (C4).

A comparação paritária dos "elementos de decisão" se constitui em um julgamento comparativo através da atribuição, pelos atores envolvidos, de pesos que determinam a importância relativa de cada elemento de um nível hierárquico em relação a cada elemento no nível seguinte.

Os entrevistados foram questionados quanto à importância (peso) dos critérios e das alternativas para gestão, numa perspectiva geral e de cada uma em relação às outras. Estes pesos foram determinados por uma escala de 1 a 9 (tabela 3), e foram utilizados para formar uma matriz de comparação paritária (Saaty, 1991). A técnica gera uma matriz quadrada, cujos elementos são os pesos relativos atribuídos à comparação entre dois elementos de decisão. A matriz foi normalizada pela transformação proporcional dos valores, de modo que a soma dos elementos da matriz fosse igual a 1 .

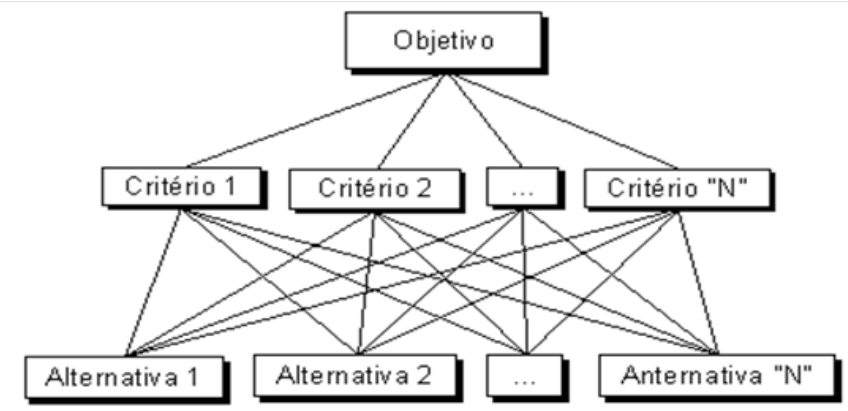

Figura 2. Estrutura Hierárquica da técnica do Processo Analítico Hierárquico (PAH). Fonte: Saaty (1991).

Figure 2. Hierarchy Structure of Analytical Hierarchy Process (AHP) technique. Source: Saaty (1991).

Em nenhum momento esta técnica tem a intenção de julgar as diferentes opinióes dos usuários em detrimento da melhor alternativa de gestão. O foco do $\mathrm{PAH}$ é avaliar os critérios prioritários sob o ponto de vista dos diversos atores sociais, de modo a recomendar açóes de gestão que minimizem conflitos e que sejam sustentáveis.

Uma vez construída e normalizada a matriz de comparação paritária, foram calculados os autovalores (W) e autovetores (T), através da soma (W) e média (T) dos pesos em cada linha da matriz. $\mathrm{O}$ autovetor $(\mathrm{T})$ representa, portanto, a importância relativa do critério analisado para que a meta principal seja atingida (Saaty, 1991). Índices de consistência inerentes à técnica também foram calculados e são apresentados nos resultados.

Além dos resultados de hierarquizaçấo do PAH, foram realizadas adicionalmente análises multivariadas de agrupamento (cluster) e escalonamento multi-dimensional não-paramétrico (nMDS), por meio do software Past (versão 2.14), no intuito de visualizar a relaçóes de proximidade entre as alternativas de gestão, baseando-se no grau de importância fornecido pelos diferentes atores sociais.

\section{RESULTADOS}

\subsection{Alternativas para gestáo da pesca artesanal}

A partir das respostas fornecidas nas entrevistas, foi possível elencar 12 alternativas relacionadas à gestáo da pesca artesanal na Costa da Paraíba. A tabela 4 apresenta uma breve descrição das alternativas e exemplos de relatos realizados pelos pescadores.

\subsection{Respostas do Processo Analítico Hierárquico (PAH)}

\subsection{1. Árvore de decisáo}

As 12 alternativas foram agrupadas pelos 4 critérios selecionados (ambiental, econômico, social e político). Os critérios foram ordenados hierarquicamente na árvore de decisão (figura 3) a partir da intensidade da importância de cada critério (ver tabela 3). A árvore de decisão foi composta por três níveis hierárquicos. No primeiro nível, apresentase o objetivo principal deste trabalho, a gestão da pesca artesanal na Costa da Paraíba, em busca de que esta atividade possa ser realizada de modo a garantir seu desenvolvimento 
Tabela 3. Escala padrão de comparação usada no PAH. Fonte: Saaty (1991).

Table 3. Semantic scale used in AHP. Source: Saaty (1991).

\begin{tabular}{lll}
\hline $\begin{array}{l}\text { Intensidade da } \\
\text { Importância }\end{array}$ & Definiçáo & Explicaçáo \\
\hline 1 & Igual importância & As duas atividades contribuem igualmente para o objetivo \\
\hline 3 & $\begin{array}{l}\text { Importância fraca de uma sobre } \\
\text { a outra }\end{array}$ & $\begin{array}{l}\text { A experiência e o julgamento favorecem levemente uma } \\
\text { atividade em relação à outra }\end{array}$ \\
\hline 5 & Importância forte ou essencial & $\begin{array}{l}\text { A experiência e o julgamento favorecem fortemente uma } \\
\text { atividade em relação à outra }\end{array}$ \\
\hline 7 & $\begin{array}{l}\text { Importância muito grande ou } \\
\text { demonstrada }\end{array}$ & $\begin{array}{l}\text { Uma atividade é fortemente favorecida; sua dominação de } \\
\text { importância é demonstrada na prática }\end{array}$ \\
\hline $2,4,6,8$ & Importância absoluta & $\begin{array}{l}\text { A evidência favorece uma atividade em relação à outra com o } \\
\text { mais alto grau de afirmação }\end{array}$ \\
\hline
\end{tabular}

e sustentabilidade. No segundo nível, foram selecionados quatro critérios, de modo que pudessem abranger as várias dimensóes envolvidas na pesca. No terceiro e último nível, encontram-se as alternativas para a gestáo da pesca sugeridas pelos próprios pescadores e demais atores envolvidos.

\subsubsection{Comparação dos critérios em relaçáo à meta principal}

A comparação paritária dos critérios está representada a partir das matrizes de julgamento (tabela 5), comparando os critérios par-a-par. A partir desses valores, foi construída a matriz de priorizaçáo dos critérios (tabela 6). Nestes resultados, o autovalor ( $\mathrm{T}$ ) é o parâmetro mais representativo, pois indica a prioridade de um critério em relação aos outros.

$\mathrm{Na}$ análise de priorização dos critérios (tabela 6), verificou-se que a dimensão política (C4) apresentou $47 \%$ de prioridade, dentre as reivindicaçóes para minimizar os conflitos que perpassam o trabalho na pesca, seguida da questão ambiental (C1), com 28\%. As dimensóes econômica e social (C2 e $\mathrm{C} 3$ ) requerem respectivamente $16 \%$ e $10 \%$ dos esforços direcionados à gestão pesqueira.

\subsubsection{Comparação das alternativas em relação aos critérios e à meta principal}

A mesma sequência de cálculos do PAH foi realizada para as alternativas de gestão, sendo apresentados na tabela 7, os resultados finais de priorização das alternativas em relação aos critérios. Os autovalores $(\mathrm{T})$ de cada alternativa são expressos para cada critério e no âmbito global, sendo possível constatar quais alternativas atendem melhor aos critérios propostos.

Quanto à dimensão ambiental $(\mathrm{C} 1)$, foram prioritárias as alternativas preservação das espécies (A1, 21\%), criação de recifes artificiais (A2,16\%), e gestão e políticas públicas (A11, 13\%). A priorização desta última evidencia a interdependência dos critérios, neste caso, nas dimensóes política e ambiental.

A dimensão econômica (C2) demonstrou como prioritárias as alternativas aumento do lucro e a agregação de valor ao pescado (A5, 21\%), preservação das espécies (A1, $15 \%)$ e gestão e políticas públicas (A11, 14\%), novamente evidenciando a inter-relação das dimensões ambientais e políticas.

Quanto à dimensão social (C3), cinco alternativas apresentaram semelhantes graus de prioridade: $\mathrm{O}$ assistencialismo social e qualidade de vida das comunidades (A7, 16\%), a preservaçáo dos aspectos culturais (A8, 15\%), treinamento, capacitação e educação ambiental para os pescadores (A9, 15\%), e mais uma vez, gestão e políticas públicas (A11, 15\%) e preservação das espécies (A1, 13\%).

Quanto à dimensão política, constatou-se a importância da alternativa Gestão e políticas públicas (A11, 22\%), seguida da organização do sindicato e colônia de pescadores (A10, 15\%), do monitoramento e fiscalização das atividades de pesca (A12, 15\%), e da preservação das espécies (A1, 15\%). Estes resultados evidenciam a importância de açóes conjuntas para minimizar conflitos políticos.

A priorização global (VP) das alternativas em relação à meta principal determinou a alternativa gestão e políticas públicas (A11, 18\%) como a prioritária em relação a todas as alternativas elencadas para a gestão da pesca artesanal no litoral da Paraíba. Somam-se a esta alternativa a preservação das espécies (A1, 16\%) e o monitoramento e fiscalização da pesca $(\mathrm{A} 12,11 \%)$.

\subsection{Análise estatística multivariada}

A análise de agrupamento e o gráfico de MDS (figura 4) demonstram um grupo consistente formado por cinco alternativas de gestão: Agregação de valor, Assistência social, Gestão compartilhada, Conservação das espécies e Fiscalização/Monitoramento. Nessa abordagem gráfica, quanto mais próximas as alternativas se localizam no gráfico mais representativas e correlacionadas estão para alcançar a gestão pesqueira. Os resultados reforçam a importância da interligaçáo dessas medidas junto ao modelo de gestão que foi priorizado. Estas alternativas, além de interdependentes foram as medidas melhor avaliadas como prioritárias para minimizar os problemas atuais para o setor da pesca no Estado. 
Tabela 4. Alternativas elencadas pelos atores sociais para gestão da pesca artesanal na costa da Paraíba, número de vezes que a alternativa foi citada ao longo da pesquisa e exemplo de relatos de pescador.

Table 4. Alternatives listed by stakeholders for artisanal fisheries management in Paraiba Coast, number of times the alternative was cited during surveys and examples of fishermen quotations.

\begin{tabular}{l}
\hline Alternativas \\
\hline A1. Conservaçáo e preservaçáo das espécies - medidas de ordenamento e conservação das \\
espécies, que visam a sustentabilidade dos estoques explotados (explorados economicamente). \\
Exemplos incluem a criação de seguro defeso, o uso de artes de pesca seletivas (que preservem \\
indivíduos jovens) e determinação do tamanho mínimo de captura para espécies ameaçadas \\
ou sobrexplotadas.
\end{tabular}

A2. Criaçáo de recifes artificiais - medidas estruturais como a construção de recifes artificiais na plataforma continental da Paraíba, ou o afundamento de blocos, feitos de material ecologicamente correto, visando criar áreas de concentração da biota marinha, especialmente das espécies-alvo da pesca, minimizando os impactos antrópicos nos recifes costeiros naturais.

A3. Criação de Unidades de Conservação (UCs) e Zoneamento Ecológico Econômico (ZEE) - a criação de UCs (áreas protegidas) de uso sustentável ou estratégias de ZEE na zona costeira, incluindo o território marítimo, devido à necessidade de proteção urgente dessas áreas, garantindo a permanência de áreas com alta biodiversidade para geraçôes futuras. Além de garantir a sustentabilidade das atividades realizadas pelas comunidades locais de pescadores.

A4. Maricultura - a maricultura de base familiar, ou através de associaçóes e cooperativas, pode ser uma alternativa para complementar a renda dos pescadores artesanais, além de criar novos campos de trabalho no setor pesqueiro e ainda envolver estratégias para o repovoamento das populações naturais.

A5. Agregaçáo de valor/Aumento do lucro - o processamento e beneficiamento do pescado, a comercialização com menor participação de intermediários (atravessadores) e aumentar o esforço de captura (aumentar a produção), são alternativas para melhorar as condiçōes de vida dos pescadores, aumentando o lucro das pescarias.

A6. Projetos de financiamento/Incentivos fiscais - essa alternativa objetiva fomentar e atrair incentivos fiscais para o desenvolvimento do setor pesqueiro artesanal para que possam ser investidos na melhoria do trabalho, bem como, facilitar o acesso aos projetos do Governo. Como principal reivindicação dos pescadores, o investimento em projetos para a compra de embarcaçóes e materiais de pesca.

A7. Qualidade de vida e Assistência social - melhoria das condiçóes de vida dos pescadores, facilitando, por exemplo, o acesso à saúde, educação e a melhores condiçóes higiênicas e sanitárias. Foi citada também a melhoria da infraestrutura das comunidades com destaque para a abertura de postos de saúde voltados ao atendimento das doenças frequentes em pescadores, como problemas na pele, visão e articulaçôes.

A8. Preservaçáo dos aspectos culturais - existe a preocupação de manter viva a cultura dos pescadores, seus rituais de fé, manifestaçôes culturais, folclóricas e memórias de sua tradição, bem como o conhecimento ecológico natural. Sugere-se o desenvolvimento de projetos de valorização do pescador e divulgação dos seus trabalhos, como artesanatos e comidas típicas.

A9. Treinamento e Capacitaçáo/Educação ambiental - iniciativa de cursos e treinamentos que capacitem os pescadores, tanto para melhoria das condiçóes de trabalho como para a conscientização ambiental. Destaque para a criação de mecanismos de transmissão de informação e troca de conhecimento entre os pescadores e demais atores envolvidos na pesca.

A10. Funçáo da Colônia/Sindicato/Cooperativa - fortalecimento da classe profissional dos pescadores artesanais através das colônias de pescadores, o estímulo à prática do cooperativismo e o reconhecimento de uma identidade de classe. Entre as sugestôes, surge a transparência da administração e "despartidarização" da colônia como medida urgente a ser trabalhada.

A11. Gestáo e Políticas públicas - necessidade de analisar o modelo de gestão e ordenamento pesqueiro, as formas de trabalho, o comprometimento e os projetos que vêm sendo desenvolvidos pelos órgãos gestores públicos atuais, com ênfase e divulgação da Gestão Compartilhada. A principal reivindicação foi a criação de espaços democráticos para discussão de temas voltados para o desenvolvimento do setor e abertos à opiniáo da sociedade.

A12. Monitoramento e Fiscalização - melhoria na fiscalização realizada pelos órgãos gestores competentes, nas áreas de pesca e locais de comercializaçáo de pescados (peixarias, bares, restaurantes e mercados) bem como, no setor administrativo dos próprios órgấos gestores e colônias de pesca. A principal reivindicação foi evitar a concessão de carteiras e benefícios de pesca a pessoas indevidas.
$\mathrm{N}^{\circ}$ de citaçóes e alguns relatos de pescadores:

77 citaçóes - "A gente tem que cuidá dos peixe, pra não faltar depois"; "A malha fina pega peixe muito pequeno, tem que aumentar pra pegar peixes maiores, e esperar o pequeno crescer"; "Era bom fazer o defeso, como o da lagosta, pra alguns peixes que tão se acabando".

08 citaçôes - "tem uns blocos aí, já prontos, podia afundar pra fazer uns pesqueiros"; "Quando tem pedra dá muito mais peixe que na lama"; "Tem uns pescadores que afundam coisa velha, pneu, pra fazer uns criatório de peixe, mas, era bom que fosse bem grande pra mais gente pescar lá".

05 citaçôes - "Tem um pessoal aqui indo tudo embora pra cidade, porque um hotel ai ta comprando as casas tudo, era bom fazer igual a Barra de Mamanguape só fica lá quem é pescador"; "Os políticos nem ligam, as fazenda de camarão tão acabando com o mangue da gente, não ajuda nada, eles podiam cuidá, nera?".

05 citaçóes - "Os pescadores podiam se organizar e ter uns cultivos desses de camaräo e peixe, pra quando a maré tivesse fraca".

39 citaçôes - "Era pro ministério da pesca dá uns barco maior pra gente pescar mais longe, que esses barquinhos da gente näo aguenta não"; "tem que aumentá o preço do marisco porque tem pouco, num dá pra nada".

25 citaçōes - "O governo tinha que liberar um dinheiro ai,... pra comprar barco e material de pesca"; "Uns pescadores tiraram um empréstimo pelo banco, e nem paga, mas pra mim não chegou um real'.

40 citaçôes - "As casas tão caindo e ninguém faz nada por nós, num pode dá uma chuva que aqui fica tudo alagado, teve pescador que perdeu tudo"; "Não tem escola, nem postim de saúde, não tem nada, eu tenho que ir na cidade pra tudo, e sem dinheiro fica dificil'.

19 citaçôes - "Esses meninos mais moço, não querem pescar mais não, só fica na frente da televisão"; "Eu não quero meus filhos aqui não, botei eles pra estudar pra ver se tem futuro".

32 citaçōes - “... precisava de alguém para ensinar a usar o GPS, os pescadores que ganharam, venderam tudim, porque não sabia usar direito"; "Era pra ter uns cursos pra falar sobre essas coisas novas da pesca".

23 citaçóes - "A colônia não serve pra nada, não faz nada pra quem é pescador de verdade"; "Aquilo é uma enganaçâo, diz que vai vim dinheiro pro pescador e nada, até a carteira da minha filha que é marisqueira não deram".

21 citaçōes - "O Governo tá investindo na pesca, eu vejo na televisão, agora a gente aqui não fica sabendo de nada, não recebe nada"; "Eu fui lá no ministério dizer que o defeso da lagosta ta errado, aqui a lagosta em agosto ainda tá ovada, mas ele náo escuta a gente, por isso ta desse jeito, acabando com tudo".

74 citaçôes - "Tem um monte de gente ai dizendo que é pescador, mas num é não, é só pra receber o seguro"; "Os homi do IBAMA, pensa que a gente é marginal, bota logo a arma na cara da pessoa". 


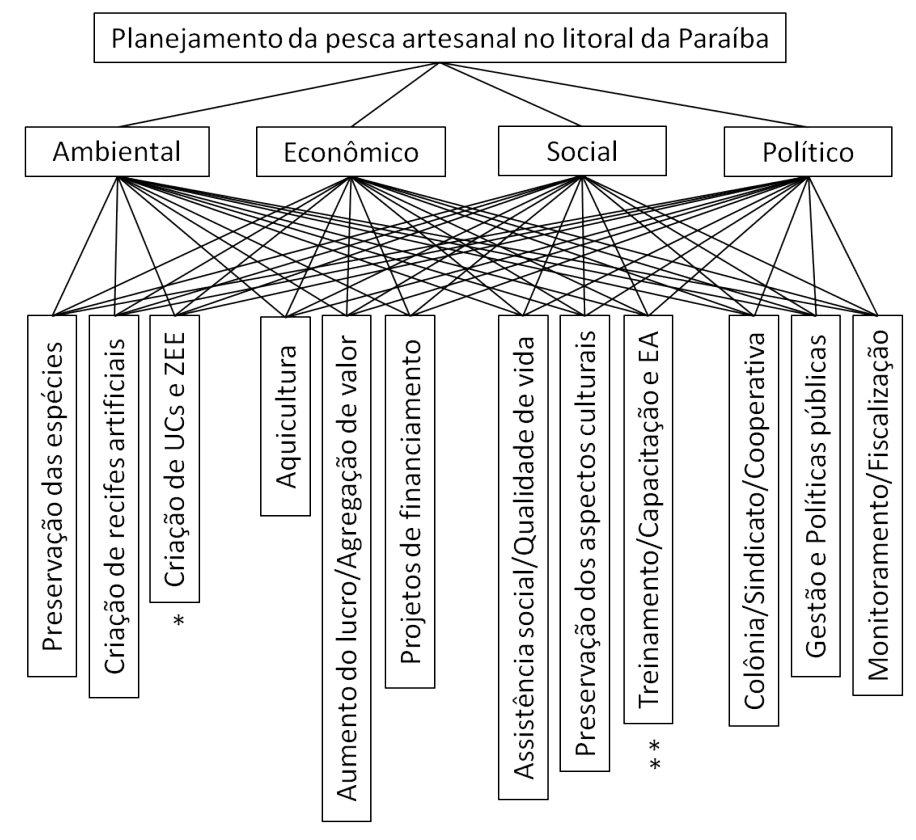

Figura 3. Árvore de decisão para gestão da pesca artesanal na costa da Paraíba.

Figure 3. Hierarchical decision tree for artisanal fisheries management in Paraíba Coast

* Criação de Unidades de Conservação e Zoneamento Ecológico Econômico (ZEE);

** Treinamento/Capacitação e Educação Ambiental.

Tabela 5. Matrizes de julgamento do PAH a partir dos critérios (C) de ponderação usados e sua comparação par-a-par (à esquerda) e normalizados (à direita) para a gestão da pesca artesanal na costa da Paraíba, Brasil.

Table 5. Judgment matrices using the established criteria $(C)$ of weighting and its pairwise comparisons (left) and normalized (right) for artisanal fisheries management in Paraiba Coast, Brazil.

\begin{tabular}{c|c|c|c|c} 
& $\mathbf{C 1}$ & $\mathbf{C} 2$ & $\mathbf{C 3}$ & $\mathbf{C 4}$ \\
\hline $\mathbf{C 1}$ & 1 & 3 & 2 & $1 / 2$ \\
\hline $\mathbf{C} 2$ & $1 / 3$ & 1 & $1 / 2$ & $1 / 4$ \\
\hline $\mathbf{C 3}$ & $1 / 2$ & 2 & 1 & $1 / 3$ \\
\hline $\mathbf{C} 4$ & 2 & 4 & 3 & 1 \\
\hline Total & 3,83 & 10,0 & 6,50 & 2,08
\end{tabular}

\begin{tabular}{c|c|c|c|c} 
& $\mathbf{C 1}$ & $\mathbf{C 2}$ & $\mathbf{C 3}$ & $\mathbf{C 4}$ \\
\hline $\mathbf{C 1}$ & 0,26 & 0,30 & 0,31 & 0,24 \\
\hline $\mathbf{C 2}$ & 0,09 & 0,10 & 0,08 & 0,12 \\
\hline $\mathbf{C 3}$ & 0,13 & 0,20 & 0,15 & 0,16 \\
\hline $\mathbf{C 4}$ & 0,52 & 0,40 & 0,46 & 0,48 \\
\hline Total & 1,00 & 1,00 & 1,00 & 1,00
\end{tabular}

Tabela 6. Priorização parcial dos critérios (C) em relação ao objetivo de gestão da pesca artesanal na costa da Paraíba, Brasil. Autovalor (W); autovetor (T); autovalor máximo ( $\lambda$ max); Índice de inconsistência (IC); Índice de consistência Randômico (IR) e Grau de inconsistência (RC).

Table 6. Partial prioritization of the criteria $(C)$ in relation to goal management of artisanal fisheries in Paraiba coast, Brazil. Eigenvalue (W); eigenvector (T) maximum eigenvalue ( $\lambda$ max); inconsistency index (CI); Random Consistency Index (RI) and degree of inconsistency (RC).

\begin{tabular}{c|c|c|c|c|c|c} 
& $\mathrm{W}$ & $\mathrm{T}$ & $\lambda \max$ & $\mathrm{IC}$ & $\mathrm{IR}$ & $\mathrm{RC}$ \\
\hline $\mathrm{C} 1$ & 1,11 & 0,28 & 1,06 & & & \\
\hline $\mathrm{C} 2$ & 0,38 & 0,10 & 0,96 & & & \\
\hline $\mathrm{C} 3$ & 0,64 & 0,16 & 1,05 & & & \\
\hline $\mathrm{C} 4$ & 1,86 & 0,47 & 0,97 & & & \\
\hline Total & 4 & 1 & 4,04 & 0,013 & 0,9 & 0,015
\end{tabular}


Tabela 7. Priorização e normalização dos autovalores (T) das alternativas (A) em relação aos critérios $(\mathrm{C})$ e priorizaçáo global (Vetor prioridade, $\mathrm{VP}$, em negrito) em relação à meta de gestão da pesca artesanal na costa da Paraíba, Brasil.

Table 7. Priorization and normalization of eigenvalues $(T)$ for the alternatives $(A)$ in relation to criteria (C) and global priorization (Priority vector, VP, in bold) towards the artisanal fisheries management in Paraíba Coast, Brazil.

\begin{tabular}{c|c|c|c|c} 
& $\mathbf{C 1}$ & $\mathbf{C 2}$ & $\mathbf{C 3}$ & $\mathbf{C 4}$ \\
\hline $\mathbf{A 1}$ & 0,21 & 0,15 & 0,13 & 0,15 \\
\hline $\mathbf{A 2}$ & 0,16 & 0,03 & 0,03 & 0,03 \\
\hline $\mathbf{A 3}$ & 0,12 & 0,02 & 0,02 & 0,03 \\
\hline $\mathbf{A 4}$ & 0,02 & 0,13 & 0,02 & 0,02 \\
\hline $\mathbf{A 5}$ & 0,06 & 0,21 & 0,05 & 0,06 \\
\hline $\mathbf{A 6}$ & 0,05 & 0,13 & 0,05 & 0,05 \\
\hline $\mathbf{A 7}$ & 0,08 & 0,06 & 0,16 & 0,07 \\
\hline $\mathbf{A 8}$ & 0,03 & 0,02 & 0,15 & 0,02 \\
\hline $\mathbf{A 9}$ & 0,03 & 0,03 & 0,15 & 0,04 \\
\hline $\mathbf{A 1 0}$ & 0,02 & 0,02 & 0,03 & 0,15 \\
\hline $\mathbf{A 1 1}$ & 0,13 & 0,14 & 0,15 & 0,22 \\
\hline $\mathbf{A 1 2}$ & 0,08 & 0,06 & 0,06 & 0,15 \\
\hline & & & & \\
\hline IC & 0,10 & 0,04 & 0,05 & 0,04 \\
\hline IR & 1,51 & 1,51 & 1,51 & 1,51 \\
\hline $\mathbf{R C}$ & 0,07 & 0,03 & 0,04 & 0,03
\end{tabular}

\begin{tabular}{c|c|c|c|c|c} 
& $\mathbf{C 1}$ & $\mathbf{C 2}$ & $\mathbf{C 3}$ & $\mathbf{C 4}$ & $\mathbf{V P}$ \\
\hline $\mathbf{A 1}$ & 0,06 & 0,01 & 0,02 & 0,07 & $\mathbf{0 , 1 6}$ \\
\hline $\mathbf{A 2}$ & 0,05 & 0,00 & 0,00 & 0,01 & $\mathbf{0 , 0 7}$ \\
\hline $\mathbf{A 3}$ & 0,03 & 0,00 & 0,00 & 0,01 & $\mathbf{0 , 0 5}$ \\
\hline $\mathbf{A 4}$ & 0,00 & 0,01 & 0,00 & 0,01 & $\mathbf{0 , 0 3}$ \\
\hline $\mathbf{A 5}$ & 0,02 & 0,02 & 0,01 & 0,03 & $\mathbf{0 , 0 8}$ \\
\hline $\mathbf{A 6}$ & 0,01 & 0,01 & 0,01 & 0,02 & $\mathbf{0 , 0 6}$ \\
\hline $\mathbf{A 7}$ & 0,02 & 0,01 & 0,03 & 0,03 & $\mathbf{0 , 0 9}$ \\
\hline $\mathbf{A 8}$ & 0,01 & 0,00 & 0,02 & 0,01 & $\mathbf{0 , 0 5}$ \\
\hline $\mathbf{A 9}$ & 0,01 & 0,00 & 0,02 & 0,02 & $\mathbf{0 , 0 6}$ \\
\hline $\mathbf{A 1 0}$ & 0,01 & 0,00 & 0,00 & 0,07 & $\mathbf{0 , 0 8}$ \\
\hline $\mathbf{A 1 1}$ & 0,04 & 0,01 & 0,02 & 0,10 & $\mathbf{0 , 1 8}$ \\
\hline $\mathbf{A 1 2}$ & 0,02 & 0,01 & 0,01 & 0,07 & $\mathbf{0 , 1 1}$
\end{tabular}

Distância
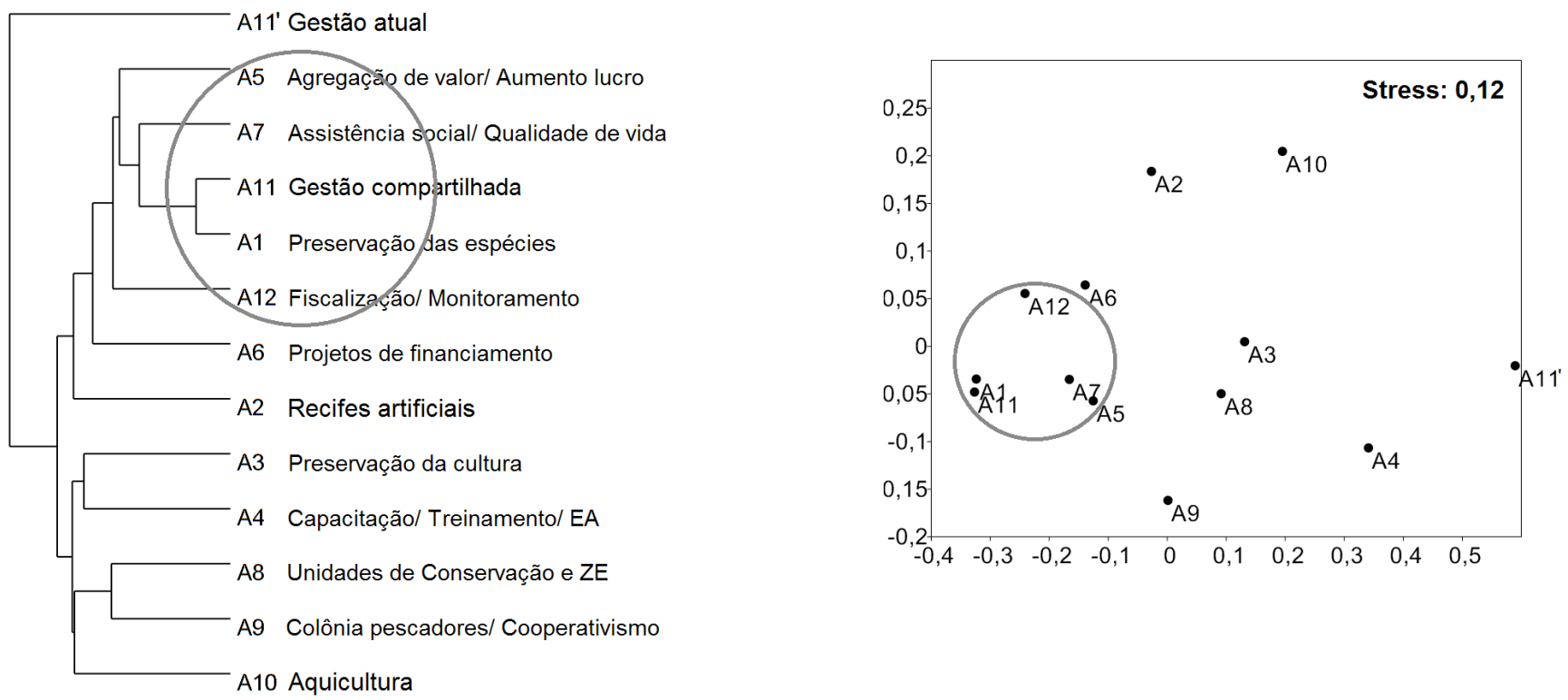

Figura 4. Análise de agrupamento e Escalonamento Multidimensional (distância euclidiana) das alternativas de gestão analisadas para a pesca artesanal na Costa da Paraíba, Brasil.

Figure 4. Cluster analysis and non-metric Multi-Dimensional Scaling plot (euclidean distances) for management alternatives to artisanal fisheries in Paraiba Coast, Brazil. 


\section{DISCUSSÃO}

O presente estudo abordou a gestão da pesca artesanal na Costa da Paraíba, com base nos conhecimentos teórico e prático dos diversos atores sociais envolvidos. São frequentes as situaçóes em que o governo subestima a capacidade dos pescadores e da comunidade pesqueira, bem como sua base de conhecimento tradicional e informal (Pomeroy, 1995). Diante dessa realidade, a técnica do PAH (Saaty, 1977) foi utilizada para estimular o desenvolvimento de alternativas sustentáveis para o manejo pesqueiro, de forma integrada, retirando o pescador da condição de mero expectador, para a condição de tomador de decisão junto aos órgãos gestores competentes.

Esse tipo de gestão pesqueira compartilhada pode ser entendido como um acordo ou parceria, onde todos os atores compartilham a responsabilidade e a autoridade para tomar decisões (Pinkerton, 1989; Pomeroy \& Berkes, 1997; Berkes \& Folke, 1998; Jentoft et al., 1998; Begossi, 2006; Pomeroy \& Rivera-Guieb, 2006; Kalikoski et al., 2009). Atualmente estamos passando por um momento de transição, deixando o modelo centralizado pelos governantes, e passando para o modelo compartilhado entre governantes, gestores e pescadores. Em 2009, foi publicado o decreto que regulamenta a Gestão Compartilhada do uso sustentável dos recursos pesqueiros no Brasil (Decreto $\mathrm{n}^{\circ}$ 6.981), definido como o processo de compartilhamento de responsabilidades entre representantes do Estado e da sociedade civil organizada (MPA-DF, 2009a). Isso inclui as agências do governo, comunidades de pescadores locais, organizações não-governamentais (ONGs), instituiçôes de pesquisa, proprietários de embarcação, comerciantes de pescados e instrumentos de pesca, estabelecimentos turísticos, instituiçóes financeiras, etc. Segundo a FAO (2010), a importância da gestão compartilhada vai além do simples acesso à tomada de decisóes, pois acarreta na redistribuição de poder entre os atores sociais, processo conhecido como "empoderamento" (do inglês, "empowerment"), que pode ocorrer nas comunidades pesqueiras tanto em nível coletivo quanto individual (Berkes et al., 2001; Jentoft, 2005).

Os resultados do PAH no presente estudo apontaram as dimensóes política e ambiental como as mais urgentes para o alcance de uma gestáo sustentável da pesca. Isso foi observado tanto na priorização dos critérios (C4, político, e C1, ambiental) como na priorização das alternativas (A11, gestão e políticas públicas; A1, preservação das espécies; e A12, monitoramento e fiscalização). Ressalta-se aqui a importância de tratar estas questóes em nível local, a fim de que decisóes sejam tomadas de forma consciente e alicerçadas na sustentabilidade.

Segundo a legislação brasileira, os recursos pesqueiros são um bem da União e, por consequência, a pesca é uma concessão do Estado. Essa assertiva leva ao entendimento de que é o Estado, em última instância, o responsável pela promoção da gestão sustentável dos recursos pesqueiros (DiasNeto, 2010). Com esse intuito, o Estado cria programas de incentivo para a preservação das espécies. Como exemplo, cita-se o período de defeso (MPA-DF, 2009b), que é a paralisaçáo temporária da pesca de uma espécie durante seu período de reprodução. Durante o defeso, os pescadores recebem um benefício no valor de um salário mínimo para não capturar a espécie.

Dentre os problemas relacionados aos programas de incentivo, está a concessão de carteiras de pescador a pessoas indevidas, "falsos pescadores", estas pessoas falsificam informações em busca de benefícios como seguro desemprego, seguro saúde, seguro defeso e aposentadoria. $\mathrm{O}$ sucesso da gestâo pesqueira depende também da cooperação e participação dos pescadores na regulação, fiscalização e monitoramento dessas atividades.

A fiscalização da pesca no Estado, exercida basicamente pelo IBAMA e pela Capitania dos Portos (Marinha), tem sido mal realizada, devido à baixa capacidade de infraestrutura e tecnologia, à falta de funcionários e de domínio marítimo. A carência de infraestrutura também é percebida nas colônias de pescadores. Das 14 colônias visitadas, duas não possuem sede própria (Z12 e Z17). As demais, apesar de possuírem estrutura física, carecem de equipamentos, como computadores e materiais de escritório, e carecem de pessoal qualificado. Além disso, existe um baixo interesse social por estas entidades civis, que apesar de serem responsáveis pela classe dos pescadores, na prática, não possuem efetivo poder sindical.

A falta de diálogo entre as comunidades pesqueiras e o governo, bem como a falta de fiscalização dos programas, leva à rejeição das medidas criadas pelo governo por parte das comunidades afetadas (Diegues, 1999). A insatisfação do pescador quanto a seguir as normas de ordenamento pesqueiro aumenta, principalmente entre aqueles que não estão inseridos em programas beneficiários. $\mathrm{O}$ fato de imprimir uma cultura dependente do assistencialismo ao invés de um conhecimento sobre os direitos humanos (seguridade do pescador) vem alienando a cultura dessas comunidades, alterando as atitudes, posturas e o próprio comportamento do pescador diante das dificuldades das atividades cotidianas da pesca.

Dentro da população estudada, cerca de $40 \%$ dos pescadores estáo inseridos em programas sociais do governo (Paulo-Junior et al., 2012). Estas medidas assistencialistas, além de impregnar uma cultura consumista, que não condiz com a realidade dessas famílias, deixam de investir em outras áreas, como infraestrutura, saneamento básico, educação, atendimento a saúde, entre outros.

Torna-se evidente a necessidade do Estado e da sociedade construírem espaços de colaboração e participação na gestão (Marrul-Filho, 2003; Dias-Neto, 2010). Entretanto, tendo sido criado pela iniciativa governamental, o modelo de gestão compartilhada que mantém um direcionamento "top down" (de cima para baixo), ao invés do sentido "bottom up" (de baixo para cima), que é o ideal num sistema descentralizado. Com base nas entrevistas realizadas, algumas medidas do governo podem ser discutidas quanto ao seu real benefício.

Projetos de financiamentos e os subsídios da pesca, por exemplo, que são geridos pelo $\mathrm{MPA}-\mathrm{PB}$ no sentido de auxiliar os pescadores artesanais, na verdade favorecem setores específicos da pesca, como donos de embarcaçóes e aquicultores. Existe um alto índice de endividamento por parte dos pescadores, há pouco esclarecimento quanto à aquisição do benefício, e falta orientação quanto ao pagamento das dívidas. 
Com relação à capacitação de pescadores, existem projetos de cursos e treinamentos, basicamente sobre confecçáo de artesanatos, que são oferecidos nas comunidades pesqueiras. Estes cursos são frequentados quase sempre por mulheres, e pouco abordam questóes voltadas à educação ambiental. Segundo o MPA-PB, estão em desenvolvimento alguns projetos, como o "pescando letras" (alfabetização de pescadores). Porém, mesmo recebendo benefícios financeiros ou cestas básicas como incentivos aos estudos, a procura pelos cursos ainda é muito baixa.

Foi constatado o interesse em cursos voltados para o processamento e beneficiamento do pescado, que busquem melhorar as condiçóes de higiene, trabalho, e aumentando a renda. Esses cursos, quando desenvolvidos em cooperativa, são bastante produtivos. A procura diminui quando, entre os pré-requisitos, são exigidos conhecimentos formais de educaçáo, em virtude do baixo nível de escolaridade da população.

Quanto à aquicultura, esta atividade ainda não se consolidou como uma prática sustentável, devido à falta de organização do sistema de transferência de tecnologia; a carência de pesquisa aplicada, de ordenamento e desenvolvimento; bem como a deficiência do sistema de comercialização e distribuição dos produtos pesqueiros (Borghetti, 2000). Segundo os próprios pescadores, a prática da aquicultura acarreta na poluição das áreas de manguezais nas proximidades desses ambientes, devido à liberação dos resíduos durante a renovação da água dos viveiros.

As alternativas elencadas neste estudo se mostraram integradas e interdependentes. Nesse sentido, a gestão compartilhada parece ter um papel prioritário sobre todos os outros, na manutenção e sustentabilidade dos recursos pesqueiros, papel esse já discutido por diversos autores no Brasil e no mundo (Pinkerton, 1989; Pomeroy, 1995; Pomeroy \& Berkes, 1997; Berkes \& Folke, 1998; Jentoft et al., 1998; Berkes et al., 2001; Pomeroy et al., 2004; Begossi, 2006; Kalikoski et al., 2009).

\section{CONSIDERAÇÓES FINAIS E RECOMENDAÇŐ́ES}

Este trabalho apresenta-se como uma das primeiras iniciativas de diagnosticar o interesse dos pescadores e outros atores sociais quanto ao seu envolvimento no modelo de gestão da pesca no estado da Paraíba. Através da metodologia utilizada, foi criado um espaço participativo e democrático para a tomada de decisão, dando abertura para a continuidade de projetos na área de gestão.

No sentido de organizar as ideias em espaços democráticos, a técnica do $\mathrm{PAH}$ se mostrou uma poderosa ferramenta para a pesquisa, diante de análises práticas e rápidas que possibilitaram o tratamento de um extenso banco de dados (quantitativos e qualitativos) que envolve o trabalho de gestão.

Considerando-se a redução nos estoques pesqueiros, é notória a impossibilidade de expansão das capturas. A recuperação do setor deve ser alcançada a partir do aprimoramento dos instrumentos de gestáo, incluindo-se o ordenamento e a fiscalização, no sentido de assegurar a sustentabilidade da pesca.
Torna-se indispensável uma Gestão Compartilhada entre os pescadores e os diferentes órgãos e instituições governamentais que participam do manejo pesqueiro, a fim de intercambiar as informaçóes necessárias para o ordenamento e controle da pesca.

É preciso um trabalho de valorização cultural dos pescadores, em virtude do seu vasto conhecimento naturalístico e empírico. A comunidade pesqueira se mostrou apta a reconhecer os conflitos do setor e a contribuir para a tomada de decisóes diante de práticas específicas. Sua participação é indispensável também para que as informaçóes institucionais cheguem com maior clareza possível aos seus usuários, minimizando deturpaçóes de determinadas orientaçóes ou regulamentaçóes.

Treinamento e capacitaçáo são mecanismos importantes para trabalhar o imediatismo, a competitividade e senso conservacionista dos pescadores. Essas atividades também estimulam a participaçáo dos pescadores em espaços construídos para a tomada de decisão junto à gestão. A melhoria da fiscalização e do monitoramento da atividade pesqueira, por outro lado, é uma medida de extrema importância para a legitimação da gestão das pescarias, bem como para averiguar a concessão e respectivo porte das carteiras de pescador profissional.

\section{BIBLIOGRAFIA}

Begossi, A. (2006) - Temporal stability in fishing spots: conservation and co-management in brazilian artisanal coastal fisheries. Ecology and Society (ISSN: 1708-3087), 11(1):5, Nova Scotia, Canada. Disponível em http:// www.ecologyandsociety.org/vol11/iss1/art5/

Berkes, F.; Folke, C. (1998) - Linking sociological and ecological systems: management practices and social mechanisms for building resilience. 393p., Cambridge University Press, New York, USA. ISBN: 0-52181592-4.

Berkes, F.; Mahon, R.; McConney, P.; Pollnac, R.; Pomeroy, R. (2001) - Managing small-scale fisheries: alternative directions and methods. 304p., IDRC Books, Ottawa, Canada. ISBN: 0-88936-943-7.

Bezerra, M.C.L.; Munhoz, T.M.T. (2000) - (Coord.) Subsidios à elaboração da Agenda 21 brasileira: Gestão dos recursos naturais. Ministério do Meio Ambiente, 200p., IBAMA, Brasília, DF, Brasil. ISBN: 978-8573000955.

Borghetti, J.R. (2000) - Estimativa da pesca e aqüicultura de água doce e marinha. Série Relatório Técnico do Instituto de Pesca (ISSN: 1678-2283), 3:8-14, São Paulo, SP, Brasil. Disponível em ftp://ftp.sp.gov.br/ftppesca/relatorio_3.pdf

Cardoso, E. S. (2001) - Geografia e pesca: Aportes para um modelo de gestão. Revista do Departamento de Geografia (ISSN: 2236-2878). 14:79-88, São Paulo, SP, Brasil. Disponível em http://citrus.uspnet.usp.br/rdg/ojs/index. $\mathrm{php} / \mathrm{rdg} /$ article/view/82

Dias-Neto, J. (2010) - Gestão do uso dos recursos pesqueiros marinhos no Brasil. 242p., IBAMA, Brasília, DF, Brasil. ISBN: 85-7300-150-X.

Diegues, A.C.S. (1999) - Human population and coastal wetlands: conservation and management in Brazil. Ocean \& Coastal Management, 42(2-4):187-210. doi: 10.1016/ S0964-5691(98)00053-2 
Diegues, A.C.S. (2001) - Ecologia Humana e Planejamento Costeiro. 190p., Editora Hucitec, São Paulo, SP, Brasil. ISBN: 8587304038.

FAO (s/d) - Actitudes participativas y principios claves en la aplicación de instrumentos/métodos participativos. Food and Agriculture Organization of the United Nations, Rome, Italy. In: http://www.fao.org/Participation/espanol/ft_ princ.jsp

Freire, K.; Pauly, D. (2010) - Fishing down Brazilian marine food webs, with emphasis on the east Brazil large marine ecosystem. Fisheries Research, 105:57-62. doi: 10.1016/j. fishres.2010.02.008

Jentoft, S. (2005) - Fisheries co-management as empowerment. Marine Policy, 29:1-7. doi: 10.1016/j. marpol.2004.01.003

Jentoft, S.; McCay, B.J.; Wilson, D.C. (1998) - Social theory and fishery co-management. Marine Policy, 22(4-5):423436. doi: S0308-597X(97)00040-7

Kalikoski, D.C.; Seixas, C.S.; Almudi, T. (2009) - Gestão compartilhada e comunitária da pesca no Brasil: avanços e desafios. Ambiente \& Sociedade (ISSN:1809-4422), 12(1):151-172, Campinas, SP, Brasil. Disponível em http://www.scielo.br/pdf/asoc/v12n1/v12n1a11.pdf

Mardle, S.; Pascoe, S.; Herrero, I. (2004) - Management objective importance in fisheries: an evaluation using the Analytic hierarchy Process (AHP). Environmental Management, 33(1):1-11. doi: 10.1007/s00267-0033070-y

Marrul-Filho, S. (2003) - Crise e sustentabilidade no uso dos recursos pesqueiros. 147p., IBAMA, Brasília, DF, Brasil. ISBN: 9788573001495.

MPA-DF (2009a) - Decreto n 6.981 de 13 de outubro de 2009. Ministério da Pesca e Aquicultura. Diário Oficial da União (ISSN:1677-7042), 218(1):63, Brasília, DF, Brasil. Disponível em http://www.planalto.gov.br/ ccivil_03/_Ato2007-2010/2009/Decreto/D6981.htm

MPA-DF (2009b) - Lei n 11.959 de 29 de junho de 2009. Ministério da Pesca e Aquicultura. Diário Oficial da União (ISSN:1677-7042), 122(1):1-8, Brasília, DF, Brasil. Disponível em http:/www.planalto.gov.br/ ccivil_03/_Ato2007-2010/2009/Lei/L11959.htm

Ostrom, E. (1990) - Governing the commons: the evolution of institutions for collective action. 281p. Cambridge University Press, Cambridge, UK. ISBN: 0521405998.
Pascoe, S.; Proctor, W.; Wilcox, C.; Innes, J.; Rochester, W.; Dowling, N. (2009) - Stakeholder objective preferences in Australian Commonwealth managed fisheries. Marine Policy, 33:750-758. doi: 10.1016/j.marpol.2009.02.008

Paulo-Junior, E.P.N.; Sassi, R.; Rosa, R.S. (2012) Diagnóstico participativo da pesca artesanal na Costa da Paraíba, Brasil. In: Andrade, M.O.; Lima, G.F.C. (org.), Gestão e Desenvolvimento Socioambiental na Paraíba: Concepçóes e Práticas, pp.125-152, Editora Universitária/ UFPB, João Pessoa, PB, Brasil. ISBN: 978-85-7745699-4.

Pauly, D.; Christensen, V.; Guénette, S.; Pitcher, T.J.; Rashid-Sumaila, U.; Walters, C.J.; Watson, R.; Zeller, D. (2002) - Toward sustainability in world fisheries. Nature, 418:689-695. doi: 10.1038/nature01017

Pinkerton, E. (1989) - Co-operative management of local fisheries: new directions for improved management and community development. 299p., University of British Columbia Press, Vancouver, BC, Canada. ISBN: 0774803266.

Pomeroy, R.S. (1995) - Community-based and comanagement institutions for sustainable coastal fisheries management in Southeast Ásia. Ocean \& Coastal Management, 27(3):143-162. doi: 09645691(95)00042-9

Pomeroy, R.S.; Berkes, F. (1997) - Two to tango: the role of government in fisheries co-management. Marine policy, 21(5):465-480. doi: S0308-597X(97)00017-1

Pomeroy, R.S.; Rivera-Guieb, R. (2006) - Fishery comanagement: a practical handbook. 223p., CAB International / International Development Research Centre, Ottawa, ON, Canada. ISBN: 1-55250-184-1.

Pomeroy, R.S.; McConney, P.; Mahon, R. (2004) Comparative analysis of coastal resource co-management in the Caribbean. Ocean \& Coastal Management, 47:429447. doi: 10.1016/j.ocecoaman.2004.09.005

Rose, G. (1997) - The trouble with fisheries science. Reviews in Fish \& Fisheries, 7: 363-370. doi: 10.1023/ A:1018495929784

Saaty, T.L. (1977) - Scaling method for priorities in hierarchical structures. Journal of Mathematical Psychology, 15(3):234-281. doi: 10.1016/0022-2496(77)90033-5

Saaty, T.L. (1991) - Método de Análise Hierárquica. 367p. McGraw-Hill, Makron Books, São Paulo, SP, Brasil. 